\title{
BIOLOGIA FLORAL DE Mauritia flexuosa LIN. FIL, NA REGIÃO DE MANAUS, AM, BRASIL.
}

\author{
Eliana Fernandez STORTI ${ }^{1}$
}

\begin{abstract}
RESUMO - Foi estudada a biologia floral de Mauritia flexuosa em Manaus, Amazonas. Mauritia flexuosa é visitada por diversas espécies de insetos. Trata-se de uma espécie cantarófila, sendo seus possíveis polinizadores os coleópteros pertencentes às famílias Nitidulidae, Curculionidae e Cucujidae, que são atraídos pelo aroma de suas flores. Sendo uma espécie dióica, o sistema de reprodução empregado por Mauritia flexuosa é obrigatoriamente a xenogamia, visto que apomixia não ocorreu nesta espécie. Mauritia flexuosa é uma espécie de grande importância para as populações da Amazônia, sendo a planta que apresenta em seus frutos, a maior taxa de pró-vitamina $\mathrm{A}$ encontrada na natureza.
\end{abstract}

Palavras Chave: Buriti, Polinização, Cantarofilia, Amazônia, Biologia reprodutiva.

Floral Biology of Mauritia flexuosa Lin. Fil.In Manaus, AM. Brazil.

ABSTRACT - A study was made in Manaus. Amazonas of the floral biology of Mauritia flexuosa. Several species of insects visit Mauritia flexuosa. The plant has a cantharophylous pollination syndrome, and Nitidulidae, Curculionidae and Cucujidae are considered to be their possible pollinators, attracted through the odor of their flowers. Mauritia flexuosa is a dioecious species and allogamy is obligatory, since apomixis does not occure. Mauritia flexuosa is a specie of great importance to the Amazonian population and their fruits have the highest level of "pro-vitamin A" found in the nature.

Key-words: Buriti, Polinination, Cantarophily, Amazônia, Reproductive biology

\section{INTRODUÇÃO}

Mauritia flexuosa Linnaeus filius é uma palmeira popularmente conhecida como miriti, buriti ou buriti-do-brejo. Sua distribuição geográfica estende-se a toda a Amazônia, alcançando os seus limites, ao norte da Venezuela à Guiana Francesa, a oeste até os contrafortes andinos, ao sul até Rondônia e norte do Mato Grosso e a leste até o Amapá, Maranhão e Bahia.

Esta palmeira habita preferencialmente terrenos baixos alagáveis, margens de rios e igarapés, formando populações quase mono-específicas, às quais se dá o nome de miritizais ou buritizais.

Embora o estudo da biologia floral na família Palmae seja dificultado pela altura, presença de espinhos no estipe e folhas de certas espécies, dioicismo, dicogamia e também ao curto período em que algumas plantas se encontram em floração, existem trabalhos de espécies de interesse econômico como o coco (Cocos nucifera L.) (HEDSTROM, 1986; SHOLDT \& MITCHELL, 1967); o dendê (Elaeis guineensis Jacq.) (GENTY et al., 1986; LUCCHINI et al., 1984; SILVA et al., 1987; SYED,

Trabalho financiado parcialmente pela Fundação Banco do Brasil Convênio n. 10/1582InstitutoNacional de Pesquisas da Amazônia, Manaus - AM. 
1979), a tamareira (Phoenix dactilifera L.) (MCGREGOR, 1976) e a pupunha (Bactris gasipaes H.B.K.) (BEACH, 1984; ESSIG, 1971; MORA URPI, 1982; MORA URPI \& SOLIS, 1980).

Os primeiros trabalhos referentes à biologia floral de espécies de Palmae, como os de DELPINO (1870), consideravam estas plantas como sendo polinizadas pelo vento (anemófilas). Foi EAMES (1961) que considerou as palmeiras polinizadas primeiramente por insetos (entomófilas) e secundariamente pelo vento (MOORE \& UHL, 1982).

Uma revisão sobre estudos de polinização em Palmae, foi feita por HENDERSON (1986) que verificou existir uma diversidade de agentes polinizadores nesta família, sendo os coleópteros, abelhas e moscas os predominantes.

São raros os trabalhos de biologia floral na subfamília Calamoideae. SPRUCE (1908), observando Mauritia carana, percebeu emissão de odor nesta espécie.

Várias são as referências sobre o emprego e constituição química do buriti (CHAVES \& PECKNIC, 1946; 1949; CAVALCANTE, 1974; PRANCE \& SILVA, 1975; RIZZINI \& MORS, 1976). Tendo em vista um melhor aproveitamento econômico desta espécie, pesquisas cada vez mais intensas se tornam necessárias com o objetivo de uma exploração racional de terrenos baixos alagáveis e no manejo agrossilvicultural. Este trabalho teve como objetivo conhecer a biologia floral de Mauritia flexuosa Lin. fil., cujo aproveitamento pelas populações amazônicas já fora relevado por HUMBOLDT (1852) que a chamou "árvore da vida".

\section{METODOLOGIA}

O estudo foi realizado em população de Mauritia flexuosa situada no campus do INPA, na área da Coordenação de Pesquisas em Aquacultura, Manaus (3'08'S - 6000'W), em 1986, 1987 e 1988 e de julho a agosto de 1992.

Foram observados 12 indivíduos ( 6 masculinos e 6 femininos) de Mauritia flexuosa para o acompanhamento de sua fenologia nos três primeiros anos de estudo.

Para se estudar a biologia floral desta espécie foram construidas escadas de madeira em duas plantas masculinas e em duas plantas femininas, obtendo uma melhor visualização dos eventos florais. Os dados foram obtidos de 14 inflorescências masculinas, 11 femininas e de 11 infrutescências; também foram marcados 928 botões para se verificar a produção natural de frutos.

O horário de abertura das flores, tempo de vida da flor e da inflorescência como um todo foram observados.

Foi acompanhado o desenvolvimento de 20 espiquetas para se verificar a produção diária de flores. Também foi observado o desenvolvimento de 125 flores femininas e a receptividade do estigma foi verificada com o auxílio de uma lupa de bolso.

Dados sobre a reflexão de luz ultra-violeta nas flores foram obtidos utilizando-se hidróxido de amônia, segundo GERTZ (1938). 
A presença ou ausência de osmóforo foi detectada utilizando-se vermelho-neutro, segundo a técnica de VOGEL (1962).

Foram feitas lâminas de pólen da planta e do carregado por Apis mellifera e Trigona sp., para posterior identificação, segundo o método de Acetólise de Erdtamn, modificado por SALGADOLABOURIAU (1971).

Para testes de fertilidade dos grãos de pólen, foi utilizado o azul de algodão em lactofenol, segundo RADFORD et al. (1974) e o tetrazólio, segundo LEE (1967), em botões fechados, em flores recém abertas e abertas.

Os visitantes foram coletados com o auxílio de um frasco aspirador ou ensacando as inflorescências; posteriormente eram mantidos em vidros contendo álcool $70 \%$ ou eterizados, para finalmente serem fixados à seco. Os Curculionidae foram identificados pelo Dr. Sérgio Vanin (USP - São Paulo), outros Coleoptera, pela bióloga Nair Otaviano Aguiar (UA - Manaus) e os Hymenoptera pelo biólogo Francisco Xavier Aguillera Peralta (INPA -Manaus).

Foi observada a freqüência dos visitantes nas duas inflorescências e em relação ao total de insetos coletados. Também foi verificado o horário de visitas dos Hymenoptera. Foi anotada a frequiência dos visitantes diariamente, para ser comparada com a apresentação das flores em ambas as inflorescências.

Insetos visitantes de diferentes espécies foram marcados com Dayglo (pigmento fluorescente), em inflorescências masculinas, para posterior tentativa de captura em inflorescências femininas.

As experiências sobre o sistema de reprodução, foram feitas utilizandose saquinhos de plástico, para impedir a visita de insetos às flores femininas. Foram ensacados 100 botões para serem utilizados como controle. Para as experiências de xenogamia foram utilizadas 100 flores recém abertas em que o estigma estava receptivo, sendo que as anteras, retiradas das flores dos indivíduos masculinos observados, foram esfregadas diretamente na superfície estigmatífera. Todas as flores testadas foram ensacadas novamente.

Foram usadas também, lâminas de vidro com vaselina penduradas em várias partes da inflorescência feminina para verificarmos a ocorrência de anemofilia.

\section{RESULTADOS}

A área estudada localiza-se num baixio hidromórfico, perturbado pela ação do homem, onde corre um igarapé de aproximadamente $5 \mathrm{a} 8 \mathrm{~m}$ de largura e onde a população remanescente de Mauritia flexuosa é numerosa.

As plantas estudadas apresentam um estipe inerme e cilíndrico de até 40 metros de altura e diâmetro de aproximadamente 50 centímetros, com 20 a 25 folhas palmadas grandes.

As inflorescências masculinas e femininas de Mauritia flexuosa são do tipo interfoliar e ligeiramente semelhantes, sendo que as ráquilas das inflores- 
cências estaminadas são do tipo "catkinlike".

O período de formação de uma inflorescência masculina, até a produção de flores é de 2 a 3 meses. A floração é anual, ocorrendo de fevereiro a agosto, sendo que o mês em que ocorreu maior floração foi o de abril. Cada planta produziu de 4 a 7 inflorescências por ano, sendo que a média foi de $4,78 \pm 0,88$.

Nas plantas femininas estudadas foi observado que o periodo de formação de uma inflorescência, até a produção de flores é de aproximadamente dois meses. A produção de frutos, isto é, quando estes começam a se desprender do ráquis, varia de 9 a 12 meses. Com os dados obtidos, verificamos que o indivíduo produz frutos a cada dois anos e a produção a nível populacional é anual. A floração ocorre principalmente nos meses de abril a junho, sendo que duas das inflorescências femininas observadas, produziram flores nos meses de fevereiro e outubro. A média de inflorescências produzidas por ano foi de 4,89 $\pm 1,05$; sendo que esse número variou de 4 a 7 inflorescências por planta.

Quanto à morfologia das inflorescências masculinas e femininas e das infrutescências foram obtidos os seguintes resultados:

A média obtida do comprimento do ráquis em inflorescências masculinas foi de $3,23 \mathrm{~m}$, variando de 2,37 a $4,79 \mathrm{~m}$. Quanto ao comprimento das ráquilas foi obtida uma média de $0,87 \mathrm{~m}$, variando de 0,75 a $1,11 \mathrm{~m}$. $\mathrm{O}$ número médio de ráquilas nas inflorescências masculinas foi de 40 . $O$ número médio de espiguetas por ráquila foi de 100 .
Cada espigueta produz em média 114 flores, sendo que este número é muito variável (95 a 163 flores por espigueta), apresentando por estimativa, um número de 450000 flores por inflorescência.

A inflorescência feminina e conseqüentemente a infrutescência de Mauritia flexuosa, possui um ráquis de $2,44 \mathrm{~m}$ de comprimento em média, variando de 1,68 a $3,00 \mathrm{~m}$. O comprimento das ráquilas obtido foi de $0,99 \mathrm{~m}$, variando de $0,20 \mathrm{~m}$ (as da ponta do ráquis) a $1,37 \mathrm{~m}$ (as próximas à base do ráquis). $\mathrm{O}$ número médio de ráquilas encontrado foi de 37; variando de 18 a 43 ráquilas. Das 11 ráquilas coletadas de inflorescências femininas foi obtida uma média de 96,68 flores por ráquila, estimando-se 3612 flores por inflorescência. Foi verificado, que $1,35 \%$ das axilas produzem uma flor; $4,05 \%$ duas flores; $20,27 \%$ três flores; $54,06 \%$ quatro flores; $18,92 \%$ cinco flores e $1,35 \%$ seis flores.

Em 11 cachos de $M$. flexuosa estudados foi encontrado um número médio de 479 frutos por ráquis. Aproximadamente $14 \%$ desses frutos são deformados. Foram observadas 654 axilas com 1 fruto (52\%), 592 axilas com 2 frutos (42\%) e 12 axilas com 3 frutos $(6 \%)$. Do acompanhamento do desenvolvimento das 928 flores foi verificado que 130 produziram frutos (14\%).

As flores estaminadas de Mauritia flexuosa tem em média $0,7 \mathrm{~cm}$ de comprimento por $0,5 \mathrm{~cm}$ de largura quando abertas, apresentam o cálice tubular, trilobado; 3 pétalas elongadas 
excedendo o cálice, amarelo alaranjado, coriáceas, unidas ligeiramente na base; 6 estames, filamentos mais ou menos livres, grosso elongado, anteras basifixas com deiscência longitudinal.

As flores pistiladas são maiores que as estaminadas, têm em médias 1,7 $\mathrm{cm}$ de comprimento por $1,2 \mathrm{~cm}$ de largura, o cálice é tubular, trilobado; corola tubular com 3 valvas, amarelo alaranjado, lobos elongados distalmente; 6 estaminódios, conatos lateralmente por seus filamentos achatados e adnatos à corỏla no tubo; ovário súpero, 3-locular, triovulado, mais ou menos redondo coberto de escamas, estilete curto, estigma séssil.

As flores, tanto as masculinas como as femininas abrem das $16: 00$ às 17:00 horas. As flores masculinas duram apenas um dia. Uma espigueta dura de 5 a 12 dias, sendo que a inflorescência como um todo dura de 7 a 15 dias.

Das 20 espiguetas observadas, foi verificado que as flores masculinas abrem, em maior quantidade, nos cinco primeiros dias de vida de uma espigueta, sendo que a maior frequência ocorreu no quarto dia $(27,60 \%)$ (Tab. 1)

Tabela 1. Porcentagem de flores abertas em 20 espiguetas e dos insetos visitantes das inflorescências masculinas de Mauritia flexнosa.

\begin{tabular}{ccc}
\hline Dia & Flores abertas & Insetos visitantes \\
\hline 1 & 3,50 & 2,50 \\
2 & 12,10 & 10,49 \\
3 & 23,70 & 34,17 \\
4 & 27,60 & 32,08 \\
5 & 17,60 & 11,59 \\
6 & 8,60 & 3,07 \\
7 & 4,60 & 0,97 \\
8 & 1,60 & 0,87 \\
9 & 0,50 & 0,80 \\
10 & 0,10 & 2,03 \\
11 & 0,05 & 0,90 \\
12 & 0,05 & 0,53 \\
\hline
\end{tabular}

As primeiras flores a abrir são as localizadas próximas à base da ráquila. Ao abrir, as ‘flores estaminadas já se encontram com as anteras deiscentes, uma a duas horas depois de abertas, as anteras estão bem expostas e com qualquer movimento ou com a ação do vento os grãos de pólen se desprendem das anteras. Duram apenas um dia.

Foi observado que a inflorescência feminina expõe suas flores em cinco dias. Das 125 flores pistiladas marcadas, foi observado que a maior exposição ocorreu no primeiro dia $(45,6 \%)$ e no segundo dia (40,8\%) (Tab. 2). As primeiras flores a abrir são as localizadas próximas ao ráquis.

Tabela 2. Porcentagem de flores abertas em 125 flores marcadas e porcentagem dos insetos visitantes das inflorescências femininas de Mauritia flexuosa.

\begin{tabular}{ccc}
\hline Dia & Flores abertas & Insetos visitantes \\
\hline 1 & 45,6 & 42,59 \\
2 & 40,0 & 30,25 \\
3 & 8,8 & 17,28 \\
4 & 0,0 & 8,64 \\
5 & 3,2 & 1,23 \\
Mortas & 2,4 & - \\
\hline
\end{tabular}

A receptividade do estigma não foi facilmente percebida. As flores femininas ao abrir, apresentam o estigma amarelo claro brilhante, com uma secreção pegajosa, que gradativamente torna-se amarelo opaco e marrom, até ser observada a presença do ovário dilatado. $19 \%$ das flores apresentaram o ovário dilatado no terceiro dia após a abertura da flor, $59 \%$ no quarto dia e $22 \%$ no quinto dia após a abertura da flor.

Utilizando-se hidróxido de amônia, verificou-se que as flores masculinas 
coraram-se mais intensamente na região das pétalas e anteras e que as flores femininas coraram-se fracamente.

Desde o primeiro dia de abertura até o oitavo dia, percebeu-se a emissão de odor das flores masculinas. $\mathrm{O}$ odor das flores masculinas é bem semelhante ao das femininas, sendo muito aromático e percebido a dezena de metros de distância.

Utilizando-se o vermelho neutro, foi verificado que as flores femininas coraram-se apenas nas anteras dos estaminódios e ápice do gineceu e as flores masculinas nas antera e ponta das pétalas, indicando as áreas produtoras de odor.

Os grãos de pólen de Mauritia flexuosa medem aproximadamente $0.039 \mathrm{~mm}$, são circulares e apresentam a exina espiculada.

$\mathrm{Na}$ análise dos grãos de pólen carregados pelas abelhas visitantes das inflorescências masculinas de Mauritia flexuosa, foi observado que tanto as Apis mellifera como as Trigona (Trigona) sp., só transportavam pólen desta espécie de planta.

$O$ resultado dos testes de fertilidade dos grãos de pólen, encontram-se na Tabela 3.

Os insetos visitantes de Mauritia flexuosa encontram-se na Tabela 4.

Tabela 3. Fertilidade dos grãos de pólen de Mauritia flexuosa.

\begin{tabular}{lcc}
\hline Estágio da flor & \multicolumn{2}{c}{ Tratamento } \\
& Azul de algodão & Tetrazólio \\
\hline Botão fechado & $69 \%$ & $78 \%$ \\
Flor recém aberta & $82 \%$ & $76 \%$ \\
Flor aberta 1 a 2 horas & $79 \%$ & $7 \%$ \\
\hline
\end{tabular}

Foram capturados 51.585 insetos nas inflorescências masculinas e 6.572 nas inflorescências femininas. Os Hymentoptera só foram coletados para identificação, sua freqüência não foi determinada. a freqüência em que os visitantes ocorreram no período de vida da inflorescência masculina, encontrase na Tabela 1. A frequiência em que os visitantes ocorreram nos cinco dias de exposição das flores femininas encontra-se na Tabela 2.

Entre os coleoptera, o gênero B e C, Theantis rhombidea Casey , 1922; as duas espécies de Pariososchoenus Andrathobius sp2., Corylophidae, Scolytidae e Tenebrionidae foram coletados apenas nas inflorescências masculinas. Homalinotus hystrix Olivier, 1790; foi observado apenas em inflorescências masculinas, destruindo os botões florais. O Gênero D, Chrysomelidae e Rhyna barbirostris Fabricius, só foram observados caminhando sobre botões florais e ráquilas das inflorescências femininas e masculinas. Os demais foram encontrados em ambas inflorescências.

Os Homoptera e Diptera foram observados em ambas inflorescências e os Thysanoptera apenas nas inflorescências masculinas. Os Diptera na inflorescência masculina coletavam pólen e na feminina secreções florais, sendo que não foram observados entrando em contacto com o estigma.

Apis mellifera adansonii visita as flores masculinas, onde coleta os grãos de pólen com as mandíbulas, passa para o abdomen e depois para as corbículas em vôo estacionário defronte para 
Tabela 4. Insetos visitantes das inflorescências de Mauritia flexuosa.

\begin{tabular}{|c|c|c|}
\hline Ordem & Familia & Espécie \\
\hline Coleoptera & $\begin{array}{l}\text { Baridinae,Madarini } \\
\text { Molylinae, Clolini } \\
\text { Chrysomelidae } \\
\text { Colydiidae } \\
\text { Corylophidae } \\
\text { Cucujidae } \\
\text { Nitidulidae } \\
\text { Scolytidae } \\
\text { Tenebrionidae }\end{array}$ & $\begin{array}{l}\text { Celetes sp. } \\
\text { Phytotribus? sp. } \\
\text { Andranthobius sp. } 1 \\
\text { Andranthobius sp. } 2 \\
\text { Gênero A? } \\
\text { Gênero B? } \\
\text { Gênero C? } \\
\text { Gênero D? } \\
\text { Theantis rhomboidea } \\
\text { Parisoschoenus sp. } \\
\text { Parisoschoenus? sp. } \\
\text { Homalinotus hystrix } \\
\text { Rhyna barbirostris }\end{array}$ \\
\hline Hymenoptera & Apidae & $\begin{array}{l}\text { Apis mellifera adansonii } \\
\text { Trigona (Trigona) sp. }\end{array}$ \\
\hline $\begin{array}{l}\text { Homoptera } \\
\text { Diptera } \\
\text { Thysanoptera }\end{array}$ & & $1+2=$ \\
\hline
\end{tabular}

a flor visitada. Encontram-se presentes, em grande número desde as primeiras horas da manhã, até às 17:30 h.

Trigona (Trigona) sp. visita os dois tipos de inflorescências. Na masculina coleta grãos de pólen dos botões que estão para abrir, com o auxílio das mandíbulas e patas anteriores, depois passa para o abdomen e posteriormente para as corbículas e na feminina coleta gotículas pegajosas provenientes da abscisão de botões florais. Esteve presente em grande quantidade desde as 07:00 horas até às 17:30 horas, sendo que durante todo o período de estudo, não foi observado nenhum indivíduo desta espécie entrando em contacto com o estigma das flores de Mauritia flexuosa.

Os Coleoptera foram os insetos mais freqüentes nas inflorescências femininas e masculinas de Mauritia flexuosa $(91,9 \%)$, seguidos pelos
Homoptera $(4,4 \%)$ e os Diptera $(2,4 \%)$. A frequiência dos Thysanoptera nas inflorescências masculinas foi de $1,3 \%$. Não foi determinada a frequiência dos Hymenoptera. A Tabela 5 indica a frequêencia dos insetos visitantes das inflorescências masculinas e femininas de Mauritia flexuosa.

Tabela 5. Frequência dos insetos visitantes nas inflorescências masculinas e femininas de Mauritia flexuosa.

\begin{tabular}{lccr}
\hline & Masculina & Feminina & Total \\
\hline Nitidulidae & 53,7 & 2,2 & 55,9 \\
Curculionidae & 21,4 & 3,5 & 24,9 \\
Cucujidae & 7,8 & 1,7 & 9,5 \\
Colydidae & 0,3 & 0,4 & 0,7 \\
Scolytidae & 0,3 & & 0,3 \\
Corylophidae & 0,2 & - & 0,2 \\
Tenebrionidae & 0,1 & - & 0,1 \\
Crysomelidae & - & 0,3 & 0,3 \\
\hline Coleoptera & 83,8 & 8,1 & 91,9 \\
\hline Homoptera & 3,5 & 0,9 & 4,4 \\
\hline Diptera & 0,1 & 2,3 & 2,4 \\
\hline Thysanoptera & 1,3 & - & 1,3 \\
\hline Hymenoptera & N.D. & N.D. & N.D. \\
\hline TOTAL & 88,7 & 11,3 & 100,0 \\
\hline
\end{tabular}


Dos insetos marcados com Dayglo nas inflorescências masculinas, foram capturados apenas dois individuos da família Nitidulidae, um dia após à marcação na inflorescência feminina.

Nos testes de sistema de reprodução, foi verificado que $80 \%$ das flores onde foi efetuada a xenogamia produziram frutos. Nenhum fruto foi produzido por apomixia.

Das lâminas contendo vaselina, não se observou a presença de nenhum grão de pólen aderido à elas.

\section{DISCUSSÃO}

Mauritia flexuosa Lin. fil., pertence à subfamília Calamoideae $\mathrm{e}$ à tribo Lepidocaryeae (UHL \& DRANSFIELD, 1987). O grupo como um todo é claramente bem adaptado aos trópicos úmidos nas latitudes $25^{\circ} \mathrm{S}$ e $\mathrm{N}$, onde representantes são encontrados em regiões secas, como nas savanas da América do Sul, indicando a presença de água (MOORE JR., 1973).

Mauritia flexuosa é uma espécie dióica que não apresenta diferenças significativas entre os indivíduos masculinos e femininos. De acordo com os dados de fenologia, foi observado que a floração é anual, sendo que em um indivíduo feminino ela ocorre a cada dois anos, no final da estação chuvosa, de abril a agosto. URREGO (1987) encontrou uma fenologia semelhante na Amazônia Colombiana.

Foi verificado que em Mauritia flexuosa as flores pistiladas são maiores que as estaminadas e que as inflorescências masculinas produzem aproximadamente 125 vezes mais flores que as inflorescências femininas. Essa tendência é comum em palmeiras onde também o tamanho inicial da flor feminina é a primeira expressão da espécie para desenvolver frutos grandes (TOMLINSON, 1990).

Mauritia flexuosa apresenta o gineceu coberto de escamas. Este é um dos mecanismos de proteção ao óvulo exibido pelas palmeiras Calamoideae, grupo considerado de grau forte e diverso, quanto aos mecanismos de proteção ao óvulo e pólen, segundo UHL \& MOORE JR. (1973).

Os atrativos florais e das inflorescências das palmeiras incluem cor, tamanho, odor e aumento da temperatura acima do ambiente; recursos florais incluem pólen e néctar, enquanto que as inflorescências podem fornecer proteção, local de acasalamento e local para nutrição das larvas (TOMLINSON, 1990).

Utilizando-se Hidróxido de Amônia, verificou-se que quase não ocorre reflexão de luz ultra-violeta. As flores estaminadas coraram-se mais intensamente e portanto, atraindo uma grande quantidade de abelhas consideradas "ladrões de pólen". Na flor pistilada, onde a reflexão é mínima, existe uma indicação que não é o estímulo visual que está atraindo os visitantes.

Com a utilização do vermelho neutro, foi detectada a localização do osmóforo (células produtoras de odor), nas flores pistiladas e estaminadas. Como ocorre com Acrocomia aculeata 
(SCARIOT et al., 1991), o odor é percebido a grande distância. Portanto podemos dizer que o reconhecimento das flores pelos insetos se faz pelo estímulo olfativo. Flores polinizadas por besouros emitem um odor forte, semelhante a fruta ou aminóide (FAEGRI \& PIJL, 1979).

O estigma de Mauritia flexuosa é, segundo a classificaçao geral de HESLOP-HARRISON \& SHIVANA (1977), do tipo seco, do grupo II B, onde a superfície é distintamente papilar.

A fertilidade dos grãos de pólen de Mauritia flexuosa é relativamente alta, mas depois de duas horas de exposta a flor, apenas $7 \%$ dos grãos apresentam atividade de respiração protoplasmática, apesar de $79 \%$ possuirem conteúdo protoplasmático. Outros testes deverão ser realizados, para determinar o que está tornando estes grãos inviáveis.

A diversidade e o tamanho dos insetos visitantes de Mauritia flexuosa torna difícil o reconhecimento do seu polinizador, mas pela frequiência em que eles ocorrem nas flores estaminadas e pistiladas, podemos dizer que trata-se provavelmente de uma espécie cantarófila, sendo os coleópteros das famílias Nitidulidae, Curculionidae e Cucujidae seus possíveis polinizadores. SCARIOT et al. (1991) sugerem que Andranthobius sp., Mystrops cf. mexicana e Cyclocephala forsteri são os polinizadores efetivos de Acrocomia aculeata. Muitos dos visitantes de Mauritia flexuosa ainda continuam sendo determinados por especialista, por se tratarem de espécies ainda não classificadas.
Apis mellifera adansonii e Trigona (Trigona) sp. são apenas visitantes das inflorescências masculinas, bem como Homalinotus hystrix, que destroi seus botões florais. Abelhas, especialmente Apis são visitantes comuns para as inflorescências de palmeiras, onde procuram pólen e néctar, sendo consideradas "ladrões de pólen", porque só visitam a inflorescência na fase masculina (TOMLINSON, 1990).

Quanto ao sistema de reprodução, Mauritia flexuosa é uma espécie dióica utilizando como sistema de reprodução a xenogamia, visto que não foram formados frutos por apomixia. Anemofilia não ocorreu nesta espécie.

Mauritia flexuosa apresentou $80 \%$ de produção de frutos em condições artificiais e apenas $14 \%$ em condições naturais. $\mathrm{O}$ aborto de flores e frutos imaturos ocorre comumente em grande escala nas espécies vegetais (BAWA \& WEBB, 1984). No caso do buriti, isto provavelmente se deva à limitação do polinizador, que visita preferencialmente as flores masculinas, à baixa fertilidade dos grãos de pólen ou a outros fatores inatos.

\section{AGRADECIMENTOS}

Agradeço ao Dr. Sérgio A. Vanin, Nair Otaviano Aguiar e Francisco J. Aguilera Peralta, pela identificação dos insetos, a Antonio Carlos Marques Souza, pela confecção das lâminas de pólen, a Aline de Castro por todo apoio durante a realização deste trabalho, a Atilio Storti Filho e ao pessoal da Coordenação de Pesquisas em Aqua- 
cultura do INPA, pela colaboração no desenvolvimento do trabalho de campo.

\section{Literatura Citada}

BAWA, K.S.; WEBB, C.J. 1984. Flower, fruit and seed abortion in tropical forest trees: implications for the evolution of paternal and maternal reproductive patterns. Amer, J. Bot., 71(5): 736-751.

BEACH, J. H. 1984. The reproductive biology of the peach or "pejibayé" palm (Bactris gasipaes) and a wild congener ( $B$. porschiana) in the Atlantic lowlands of Costa Rica. Principes, 28(3): 107-119.

CAVALCANTE, P. B. 1974. Frutas comestíveis da Amazônia. II. Publ. Avulsas Mus. Par. E. Goeldi, 27: 1-73.

CHAVES, J. M.; PECKNIC, E. 1946. Estudo da composiçăo química e do valor alimentício do buriti (Mauritia sp. Mart.) Rev. Quim. Ind., 15: 140-141.

1949. Em dois frutos brasileiros, o maior potencial de pro-vitamina A que se conhece - buriti e tucumã. Rev. Quim. Ind, 18: 176-177.

DELPINO, F. 1870 . Ulteriori asservazioni e considerazioni sulla dicogamia nel regno vegetale. Atti Soc. Ital. Sci. Nat. Milano 13: 167-205 (Apud HENDERSON, A. 1986. op. cit.).

EAMES, A. J. 1961. Morphology of the angiosperms. New York, McGraw- Hill Book Co. Inc. 518 p.

ESSIG, F. B. 1971. Observations on pollination in Bactris. Principes, 15(1): 20-24.

FAEGRI, K.; PIJL, L. VAN DER. 1979. The principles of pollination ecology. Oxford, Pergamon Press. 244p.

GENTY, P.; GARZON, A.; LUCCHINI, F.; DELVARE,G. 1986. Polinización entomófila de la palma africana en América tropical. Oleagineux, 41(3): 99-112.

GERTZ, O. 1938. Ueber die Verbreitung des Anthochlors bei den Compositen. $\mathrm{Kgl}$. Fysiogr. Sällsk. Lund. Förh., 8: 62-70
(Apud SCOGIN, R,; YOUNG, D. A.; JONES JR., C. E. - 1977. Anthochlor pigments and pollination biology. II. The ultraviolet floral pattern of Coreopsis gigantea (Asteraceae). Bull. Torrey Bot. Club, 104(2): 155-159).

HEDSTROM, I. 1986. Pollen carriers of Co$\cos$ nucifera $\mathrm{L}$. (Palmae) in Costa Rica and Ecuador (Neotropical region). Rev. Biol. Trop., 34(2): 297-301.

HENDERSON, A. 1986. A review of pollination studies in the Palmae. Bot. Rev., 52(3): 221-259.

HESLOP-HARRISON, Y; SHIVANNA, K. R. 1977. The receptive surface of the Angiosperm stigma. Ann Bot., 41:12331258.

HUMBOLDT, A. von. 1852. Travels to the equinoctial regions of America (apud CORNER, E. J. H. 1966. The natural history of Palms. London, Weidenfeld and Nicolson. 396 p.

LEE, A. E. 1967. Crescimento e desenvolvimento das plantas. São Paulo, EDART - Livraria Editora Lida. 96 p.

LUCCHINI, F; MORIN, J. P; SOUZA, R. L. R.; LIMA, E. J.; SILVA, J. C. 1984. Polinização entomófila do dendê, Elaeis guineensis, e de híbridos (OxG) em plantios comerciais de Benevides, PA. EMBRAPA - Pesq. em And., 26. 9p.

MCGREGOR, S. E. 1976. Insect pollination of cultivated crop plants. Washington, Agric. Hand. no. 496. USDA. 411 p.

MOORE JR,, H. E. 1973. Palms in the tropical ecosystems of Africa and South America. In: Tropical forest ecosystems in Africa and South America: A comparative review. MEGGERS, B.J.; AYENSU,E.S.; DYCKWORTH, W.D. (eds.). Smithsonian Institution Press, Washington. p. 63-88.

; UHL, N. W. 1982. Major trends of evolution in Palms. Bot. Rev., 48(1): 1-69.

MORA URPI, J. 1982. Polinización en Bactris gasipaes H.B.K. (Palmae): Nota adicional. Rev. Biol. Trop., 39(2): $174-$ 176. 
; SOLIS, E. M. 1980. Polinización en Bactris gasipaes H.B.K. (Palmae), Rev. Biol. Trop. 28(1): 153-174.

PRANCE, G. T; SILVA, M. F. 1975. Arvores de Manaus. Manaus, INPA. 312 p.

RADFORD, A. E.; DICKISON, W. C.; MASSEY, J. R.; RITCHIE BELL, C. 1974. Vascular plant systematics. New York, Harper \& Row Publish. 891 p.

RIZZINI, C. T.; MORS, W. B. 1976, Botânica econômica brasileira. São Paulo, EPUEDUSP , $207 \mathrm{p}$.

SALGADO-LABOURIAU, M, L. 1971. Contribuição à palinologia dos cerrados. Rio de Janeiro, Academia Brasileira de Ciências. 291 p.

SCARIOT, A. O.; LLERAS, E; HAY, J. D. 1991. Reproductive biology of the Palm Acrocomia aculeata in Central Brazil. Biotropica, 23(1): 12-22.

SHOLDT, L. L.; MITCHELL, W. A. 1967. The pollination of Cocos nucifera $\mathrm{L}$. in Hawaii. Trop. Agr. Trinidad, 44(2): 133. 142.

SILVA, M. F.; MIRANDA, I. P. A.; BARBOSA, E. M. 1987. Aspectos sobre a polinização do "dendezeiro" Elaeis guineensis Jacq. e do "caiaué" Elaeis oleifera (H.B.K.) Cortés (Arecaceae). Acta Amazonica, 16/17: 209-218.

SPRUCE, R. 1908. A botanist of the Amazon and Andes. 2 vols. WALLACE, A. R. (ed.). Macmillan \& Co., Limited, London. (apud HENDERSON, A. 1986 op cit).

SYED, R. A. 1979. Studies on oil palm pollination by insects. Bull. Ent. Res, 69: 213-224.

TOMLINSON, P, B. 1990. The structural biology of Palms. Claredon Press Oxford, Oxford. 463p.

UHL, N. W.; DRANSFIELD, J. 1987. Genera Palmarum: A classification of Palm. based on the work of Harold E. Moore Jv. Allen Press, Lawrence, Kansas. 609p. ; MOORE JR., H. E. 1973. The protetion of pollen and ovules in Palms. Principes, 17(4): 111-149.

URREGO G., L. E. 1987. Estudio preliminar de la fenologia de Canaguchi (Mauritia flexuosa L.f.). Tesis, Universidade Nacional de Colombia, Facultad de Agronomia, Medellin (apud BORGTOFT PEDERSEN, H. \& BALSLEV, H. 1990. Ecuadorean Palms for agnoforestry. AAU Reports 23, Aarhus University Press. $122 p$.

VOGEL, S. 1962. Duftdrusen im Dienste der Bestaubung. Akad. Wiss. Abh. Math. Naturwiss. KI., 10: 599.763 (Apud WEBBER, A.C. 1981. Biologia floral de algumas Annonaceae na regiāo de Manaus, AM. Dissertação de Mestrado. Instituto Nacional de Pesquisas da Amazônia, Manaus, Amazonas. 83 p. 